\title{
Cardiac Memory versus Likelihood of Ischemic Heart Disease in Hypertensive Patients with Ventricular Repolarization Abnormalities after Repetitive Uniform Ventricular Extrasystoles
}

\author{
Aly Mohamad Hegazy $^{\mathrm{a}}$ Mohamad Hussein Alkandary ${ }^{\mathrm{b}}$ \\ a Non-Invasive Cardiac Laboratory and ${ }^{\text {b }}$ Department of Medicine, Farwania Hospital, Kuwait
}

\section{Key Words}

Cardiac memory $\cdot$ Hypertensive heart disease $\cdot$ Ventricular repolarization

\begin{abstract}
Objectives: To investigate the value of T-wave inversion after premature ventricular complexes (PVCs) for the prediction of hypertensive patients with a likelihood of ischemic heart disease (IHD). Patients and Methods: Ambulatory 24hour ECG, ambulatory 24-hour blood pressure (BP) recording, echocardiography, treadmill exercise ECG test and thallium-201 scintigraphy were performed for 210 hypertensive patients. Results: Predictive indices showed that persistent symmetrical T-wave inversion after repetitive uniform PVCs equaling $30 \mathrm{~min}$ can be considered an indicator for the prediction of IHD in hypertensive patients as sensitivity was $80 \%$, specificity: $73 \%$, accuracy: $78 \%$, positive predictive value: $83 \%$, and negative predictive value: $69 \%$. kappa coefficient value ( $\kappa$ ) indicated that there was good agreement between changes in ventricular repolarization after PVCs and stress thallium scintigraphy ( $\kappa=0.897)$. Receiver-operating characteristic curve data showed that the ideal cutoff value of T-wave inversion voltage to predict IHD in hypertensive patients was $2.2 \mathrm{mV}$ (sensitivity: $66 \%$ and false positive: $35 \%$, and area under curve: 0.716 ), but the ideal cutoff value of time for resolution of T-wave inversion was $34 \mathrm{~min}$ (sensitiv-
\end{abstract}

ity: $83 \%$ and false positive: $18 \%$, and area under curve: 0.873 ). Multivariate analysis revealed that T-wave inversion after repetitive uniform PVCs was significantly associated with nonsustained ventricular tachycardia, decreased parasympathetic activity, increased sympathetic activity, morning BP surge, systolic BP load $>50 \%$ and left ventricular diastolic dysfunction status. Conclusion: The data show that persistent symmetrical T-wave changes following resumption of sinus rhythm after repetitive uniform PVCs are an independent variable for the prediction of IHD in hypertensive patients.

Copyright $\odot 2007$ S. Karger AG, Basel

\section{Introduction}

The term 'cardiac memory' was described and named by Rosenbaum et al. [1] and had been reported independently by Chatterjee et al. [2]. Cardiac memory is characterized by an altered $\mathrm{T}$ wave on electrocardiogram (ECG) recorded during sinus rhythm, having been induced by a preceding period of abnormal ventricular activation.

Intermittent bundle branch block, ventricular tachycardia, ventricular pre-excitation and repeated uniform extrasystoles induce secondary T-wave changes not only during the period of the altered activation sequence but also possibly persisting after the normal supraventricular 
activation pattern resumes [3]. Previous studies have shown that patients may have transient repolarization abnormalities that mimic myocardial ischemia after resolution of abnormal ventricular activation [4]. For many years, it has been assumed that $\mathrm{T}$-wave changes are either primary or secondary in nature, and that this classification covers all possible T-wave abnormalities occurring in the human ECG [5].

The objective of this study was to investigate the value of changes in ventricular repolarization after premature ventricular complexes (PVCs) for the prediction of hypertensive patients with a likelihood of ischemic heart disease (IHD).

\section{Patients and Methods}

\section{Patients}

Two hundred and ten hypertensive patients were included in the study. All patients were evaluated clinically by history, physical examination, 12-lead ECG, plain chest X-ray and routine laboratory investigations. Exclusion criteria were patients with rheumatic heart disease, mitral valve prolapse, acute myocardial infarction, old myocardial infarction, intraventricular conduction disturbances, atrial fibrillation, left ventricular (LV) failure, acute pulmonary edema and ECG-based LV strain pattern.

\section{Twenty-Four-Hour Ambulatory ECG}

A coupling interval is an interval between the $\mathrm{R}$ wave of PVC and the $\mathrm{R}$ wave of the preceding sinus QRS complex. A compensatory pause is an interval between the $\mathrm{R}$ wave of $\mathrm{PVC}$ and the $\mathrm{R}$ wave of the following sinus QRS complex. The comparison of the morphology of $\mathrm{T}$ waves was performed between sinus beats preceding PVCs and first post-extrasystolic beats. Non-sustained ventricular tachycardia was defined as $\geq 3$ consecutive ventricular premature beats at a rate of 120 beats/min [6]. The QT interval was measured from the earliest onset of the QRS complex to the terminal portion of the $\mathrm{T}$ wave, where it met the baseline. The R-R interval from the preceding cardiac cycle was measured from the peaks of the $\mathrm{R}$ waves to correct the QT interval for heart rate (QTc). QT intervals were corrected with Bazett's formula $(\mathrm{QTc}=\mathrm{QT} / \sqrt{\mathrm{R}-\mathrm{R})}$ [7]. Time domain measures were determined from the percentage of successive R-R intervals that deviated by $>50 \%$ from the prior R-R interval ( $\mathrm{p}-\mathrm{NN} 50$ ) and the root mean square of successive R-R interval differences (rMMD) [8].

\section{Ambulatory 24-Hour Blood Pressure Monitoring}

Ambulatory blood pressure (BP) was recorded with an auscultatory device (Accutracker II). Morning BP surge is defined as the difference between the mean systolic BP during the $2 \mathrm{~h}$ after waking and arising minus the mean systolic BP during the hour which included the lowest blood pressure during sleep. BP load is the percentage of all systolic and diastolic BP recordings exceeding thresholds of $140 / 90 \mathrm{~mm} \mathrm{Hg}$ [9]. Pulse pressure was calculated as the difference between systolic and diastolic BP. Mean BP was calculated as diastolic BP plus $1 / 3 \mathrm{BP}$.
Transthoracic Echocardiography and Doppler Study

It was performed for all patients with the use of GE vivid 7 and a $3.5-\mathrm{MHz}$ phased-array transducer. The following measurements were obtained: peak velocity of the early left ventricular filling $(\mathrm{E})$, peak velocity of late left ventricular filling $(\mathrm{A})$, the ratio between early and late flow velocity (E/A) and deceleration time of E velocity.

\section{Thallium Scintigraphy}

Both stress and rest thallium-201 scintigraphy were performed for all the 210 patients and ischemia was defined as a stress perfusion defect in an area with normal perfusion at rest.

\section{Statistical Analysis}

Continuous variables are summarized as means $\pm \mathrm{SD}$. Comparison between two groups was performed with the $t$ test for continuous variables and $\chi^{2}$ test for categorical variables. A p value $<0.05$ was considered statistically significant and a $p$ value $<0.01$ was considered statistically highly significant. A stepwise multivariate regression model was used to identify possible independent variables associated with ventricular repolarization abnormalities. The strength of the association with T-wave inversion after PVCs is presented as 95\% confidence intervals. Potential confounding of clinical variables was entered as an independent variable.

The validity of T-wave inversion after repetitive PVCs to predict IHD was assessed by estimating the predictive indices and kappa coefficient ( $\kappa)$ to determine the overall agreement with the data obtained from the stress thallium scintigraphy.

Receiver-operating characteristic curve (grade of sensitivity versus false-positive results) was used to identify the sensitivity and false-positive results of certain values of the variable with area under curve and probability of error with sensitivity $100 \%$ to detect usefulness of T-wave inversion after PVCs in the hypertensive patients for prediction of IHD. Receiver-operating characteristic curve data were calculated using the likelihood ratio method.

\section{Results}

Regarding ventricular repolarization, 62 patients had symmetrical T-wave inversion and 18 patients isoelectric or biphasic T wave. Stress thallium scintigraphy was positive in 86 patients and negative in 124 patients. There was a significantly increased time needed for resolution of Twave inversion in the patients with positive $(32.5 \pm 8.9$ $\mathrm{min})$ compared to those with negative (12 $\pm 4.3 \mathrm{~min})$ stress thallium scintigraphy $(\mathrm{p}<0.05)$. There was good agreement between results of stress thallium scintigraphy and changes in the ventricular repolarization with Cohen's kappa concordance coefficient $(\kappa)=0.897$. The predictive indices showed that T-wave inversion after repetitive uniform ventricular extrasystoles is a marker for the prediction of hypertensive patients with a likelihood of IHD (table 1). 
Table 1. Indices of changes in the ventricular repolarization for the prediction of IHD in hypertensive patients

\begin{tabular}{|c|c|c|c|c|c|c|c|c|c|}
\hline Symmetrical T-wave inversion & 42 & 80 & 25 & 26 & 62 & 76 & 71 & 62 & 75 \\
\hline Isoelectric or biphasic $\mathrm{T}$-wave changes & 8 & 14 & 5 & 10 & 44 & 73 & 56 & 61 & 58 \\
\hline Deep voltage of $\mathrm{T}$-wave inversion $>0.4 \mathrm{mV}$ & 33 & 25 & 5 & 17 & 66 & 83 & 72 & 86 & 60 \\
\hline Delayed resolution of $\mathrm{T}$-wave inversion $>30 \mathrm{~min}$ & 40 & 22 & 8 & 8 & 80 & 73 & 78 & 83 & 69 \\
\hline
\end{tabular}

$\mathrm{TP}=$ True positive; $\mathrm{TN}=$ true negative $\mathrm{FN}=$ false negative $; \mathrm{FP}=$ false positive Sen = sensitivity $;$ Spec = specificity $;$ Acc = accuracy; $\mathrm{PPV}=$ positive predictive value; $\mathrm{NPV}=$ negative predictive value.

Table 2. Receiver-operating characteristic curve data to define the ideal cutoff values of the changes in repolarization for the prediction of IHD

\begin{tabular}{lllllll}
\hline Repolarization variables & $\begin{array}{l}\text { Ideal cutoff } \\
\text { values }\end{array}$ & $\begin{array}{l}\text { Sensitivity } \\
\%\end{array}$ & $\begin{array}{l}\text { Specificity } \\
\%\end{array}$ & $\begin{array}{l}\text { FPV } \\
\%\end{array}$ & \multicolumn{2}{l}{$\begin{array}{l}\text { Likelihood ratio } \\
\text { positive }\end{array}$} \\
\hline Voltage of T wave & $0.4 \mathrm{mV}$ & 87 & 70 & 30 & 2.26 & 0.457 \\
Resolution of T wave & $34 \mathrm{~min}$ & 84 & 82 & 19 & 4.31 & 0.222 \\
HR-corrected QT interval & $487 \mathrm{~ms}$ & 74 & 72 & 28 & 2.64 & 0.361 \\
\hline
\end{tabular}

The ideal cutoff value: high detection rate (sensitivity) with low false-positive results (false positive: 1 - specificity). $\mathrm{HR}=$ Heart rate; FPV = false-positive value.

\section{Receiver-Operating Characteristic Curve}

The ideal cutoff value of T-wave inversion voltage after PVCs to predict IHD in hypertensive patients was 0.4 $\mathrm{mV}$ at $86 \%$ sensitivity and $85 \%$ specificity. The ideal cutoff value of the time needed for resolution of T-wave inversion after PVCs to predict IHD in hypertensive patients was $30 \mathrm{~min}$ at $83 \%$ sensitivity and $82 \%$ specificity (table 2).

\section{Forward Stepwise Logistic Analysis}

Multivariate analysis showed that the changes in ventricular repolarization after repetitive uniform PVCs were significantly associated with non-sustained ventricular tachycardia (odds ratio, $\mathrm{OR}=1.895$ ), impaired parasympathetic activity $(\mathrm{OR}=1.861)$, increased sympathetic activity $(\mathrm{OR}=1.953)$, morning $\mathrm{BP}$ surge $(\mathrm{OR}=$ $1.832)$, systolic BP load $>50 \%(\mathrm{OR}=1.907), \mathrm{LV}$ diastolic dysfunction status $(\mathrm{OR}=1.937)$, no angiotensin receptor blockers $(\mathrm{OR}=2.654)$ and no calcium channel antagonists $(\mathrm{OR}=1.994)$ as independent variables (tables 3,4$)$.

\section{Discussion}

Our data indicated that persistent symmetrical deep T-wave inversion of more than $30 \mathrm{~min}$ after repetitive uniform PVCs is a good predictor of IHD in hypertensive patients. This finding is consistent with previous reports [10-13]. Kalbfleisch et al. [10] reported that repolarization abnormalities that are in a direction opposite to that of the previous delta wave in the same lead cannot be explained by the phenomenon of cardiac memory and may be an indication of myocardial injury. Lepeschkin [11] reported that in some cases of ventricular tachycardia, $T$ waves remain inverted for hours or days after termination of each attack, which may be explained by rapid heart rate or presumptive coronary insufficiency. Kernohan [12] reported that the post-tachycardia $T$ waves show the same direction as those of the QRS forces during the tachycardia, and this finding suggests that modulation of ventricular repolarization with accumulation and memory occurs in response to the altered ventricular activation provoked by the tachycardia. This is the basic mech- 
Table 3. Stepwise logistic multivariate analysis of patients with versus those without ventricular repolarization changes in regard to independent variables

\begin{tabular}{|c|c|c|c|c|}
\hline $\begin{array}{l}\text { Independent } \\
\text { variables }\end{array}$ & $\begin{array}{l}\text { Regression } \\
\text { coefficient }\end{array}$ & $\mathrm{p}$ value & OR & $95 \% \mathrm{CI}$ \\
\hline \multicolumn{5}{|c|}{ Non-sustained ventricular tachycardia } \\
\hline Yes & 0.1872 & $<0.05$ & 1.895 & $1.209-2.427$ \\
\hline No & 0.0532 & NS & 0.859 & $0.380-1.324$ \\
\hline \multicolumn{5}{|c|}{ Ventricular couplets } \\
\hline Yes & 0.0607 & NS & 1.121 & $0.343-1.864$ \\
\hline No & 0.0443 & NS & 0.664 & $0.042-1.366$ \\
\hline \multicolumn{5}{|c|}{ Ventricular bigeminy } \\
\hline Yes & 0.0264 & NS & 1.053 & $0.145-1.931$ \\
\hline No & 0.0543 & NS & 0.987 & $0.454-1.443$ \\
\hline \multicolumn{5}{|c|}{ Coupling interval } \\
\hline Prolonged & 0.0662 & NS & 0.987 & $0.329-1.647$ \\
\hline Short & 0.0464 & NS & 0.869 & $0.295-1.343$ \\
\hline \multicolumn{5}{|c|}{ Decreased parasympathetic activity } \\
\hline Yes & 0.1965 & $<0.05$ & 1.861 & $1.031-2.639$ \\
\hline No & 0.0443 & NS & 0.731 & $0.243-1.387$ \\
\hline \multicolumn{5}{|c|}{ Increased sympathetic activity } \\
\hline Yes & 0.1742 & $<0.05$ & 1.953 & $1.089-2.842$ \\
\hline No & 0.0328 & NS & 0.836 & $0.397-1.378$ \\
\hline
\end{tabular}

Number of observations: 210 . CI = Confidence interval.

anism underlying most cases of post-tachycardia syndrome [13].

The LV diastolic dysfunction was an independent variable associated with repolarization abnormalities after repetitive uniform PVCs. A plausible explanation is that altering ventricular activation changes stress-strain relationships in the myocardium which induces synthesis and release of angiotensin II by cardiac cells [14]. Sadoshima and Izumo [15] reported that angiotensin II had a role in the induction of repolarization abnormalities after ventricular arrhythmias. This is in agreement with our results, as multivariate analysis revealed a significant association between no history of angiotensin receptor blockers and calcium channel blockers and the development of repolarization abnormalities after PVCs. Also, Ricard et al. [16] showed that repolarization abnormalities after ventricular arrhythmias could be prevented by interfering with the renin-angiotensin II system via any of three interventions: the use of angiotensin-converting enzyme inhibitors, angiotensin II receptor blockers and the tissue chymase inhibitor, chymostatin. That chymostatin (which attenuates the conversion of angiotensin I to angiotensin II at tissue level) is a potent inhibitor of cardiac memory induction suggests that local angioten-
Table 4. Stepwise logistic multivariate analysis of patients with versus those without ventricular repolarization changes in regard to independent variables of ambulatory 24-hour BP monitoring and anti-hypertensive drugs

\begin{tabular}{|c|c|c|c|c|}
\hline $\begin{array}{l}\text { Independent } \\
\text { variables }\end{array}$ & $\begin{array}{l}\text { Regression } \\
\text { coefficient }\end{array}$ & $\mathrm{p}$ value & OR & $95 \% \mathrm{CI}$ \\
\hline \multicolumn{5}{|c|}{ Morning BP surge } \\
\hline Yes & 0.1852 & $<0.05$ & 1.832 & $1.128-2.706$ \\
\hline No & 0.0765 & NS & 0.987 & $0.265-1.487$ \\
\hline \multicolumn{5}{|c|}{ Nocturnal dipping BP } \\
\hline Yes & 0.0629 & NS & 1.165 & $0.474-1.831$ \\
\hline No & 0.0465 & NS & 0.589 & $0.168-1.043$ \\
\hline \multicolumn{5}{|c|}{ Increased pulse pressure } \\
\hline Yes & 0.0518 & NS & 0.994 & $0.225-1.614$ \\
\hline No & 0.0987 & NS & 0.839 & $0.291-1.328$ \\
\hline \multicolumn{5}{|l|}{ Systolic BP load } \\
\hline$>50 \%$ & 0.1919 & $<0.05$ & 1.907 & $1.241-2.896$ \\
\hline$<50 \%$ & 0.0575 & NS & 0.798 & $0.117-1.399$ \\
\hline \multicolumn{5}{|c|}{ Diastolic BP load } \\
\hline$>50 \%$ & 0.0954 & NS & 0.735 & $0.226-1.316$ \\
\hline$<50 \%$ & 0.0765 & NS & 0.693 & $0.277-1.107$ \\
\hline \multicolumn{5}{|c|}{ Systolic BP variability } \\
\hline$>20 \mathrm{~mm} \mathrm{Hg}$ & 0.0162 & NS & 0.884 & $0.209-1.627$ \\
\hline$<20 \mathrm{~mm} \mathrm{Hg}$ & 0.0654 & NS & 0.712 & $0.378-1.271$ \\
\hline \multicolumn{5}{|c|}{ Increased LV mass index } \\
\hline Yes & 0.0685 & NS & 0.931 & $0.343-1.567$ \\
\hline No & 0.0486 & NS & 0.806 & $0.572-1.165$ \\
\hline \multicolumn{5}{|c|}{ LV diastolic dysfunction } \\
\hline Yes & 0.1713 & $<0.05$ & 1.937 & $1.125-2.714$ \\
\hline No & 0.0765 & NS & 0.811 & $0.451-1.332$ \\
\hline \multicolumn{5}{|l|}{ ACE inhibitors } \\
\hline Yes & 0.0907 & NS & 0.769 & $0.396-1.119$ \\
\hline No & 0.0766 & NS & 0.926 & $0.254-1.743$ \\
\hline \multicolumn{5}{|c|}{ Angiotensin receptor blockers } \\
\hline Yes & 0.0636 & NS & 0.656 & $0.361-1.043$ \\
\hline No & 0.1764 & $<0.05$ & 2.654 & $1.627-3.515$ \\
\hline \multicolumn{5}{|c|}{ Calcium channel antagonists } \\
\hline Yes & 0.0692 & NS & 0.881 & $0.345-1.343$ \\
\hline No & 0.1607 & $<0.05$ & 1.994 & $1.209-2.727$ \\
\hline \multicolumn{5}{|l|}{$\beta$-Blockers } \\
\hline Yes & 0.0862 & NS & 0.792 & $0.196-1.553$ \\
\hline No & 0.0432 & NS & 0.892 & $0.123-1.676$ \\
\hline
\end{tabular}

Number of observations: 210. ACE = Angiotensin-converting enzyme; $\mathrm{BP}=$ blood pressure; $\mathrm{CI}=$ confidence interval.

sin II regulates memory induction. Also, we found no history that calcium channel blockers are an independent variable significantly associated with repolarization abnormalities. Plotnikov et al. [17], however, reported that calcium channel blockade but not $\beta$-adrenergic blockade suppresses repolarization abnormalities after ventricular arrhythmias, and long-term repolarization 
abnormalities are unaffected by angiotensin II blockade.

In this study, logistic analysis showed that an increase in sympathetic activity and a decrease in parasympathetic activity are independent variables associated with repolarization abnormalities after repetitive uniform PVCs, in agreement with results obtained by Wendkos [18].

The limitations of the study include the relatively small number of patients, only one center experience and coronary cine angiography performed for only 32 pa- tients. Also, myocardial contrast echocardiogram was not done as it detects myocardial blood flow and perfusion.

\section{Conclusion}

The data show that persistent symmetrical T-wave changes following resumption of sinus rhythm after repetitive uniform PVCs are an independent variable predicting IHD in hypertensive patients.

\section{References}

1 Rosenbaum MB, Blanco HH, Elizari MV, Lazzari JO, Davidenko JM: Electronic modulation of the $\mathrm{T}$ wave and cardiac memory. Am J Cardiol 1982;50:213-222.

- Chatterjee K, Harris AM, Davies JG, Leatham A: Electrocardiographic changes subsequent to artificial ventricular depolarization. Br Heart J 1969;31:770-779.

3 Wecke L, Gadler F, Linde C, Lundahl G, Rosen MR, Bergfeldt L: Temporal characteristics of cardiac memory in humans: vectorcardiographic quantification in a model of cardiac pacing. Heart Rhythm 2005;2:2834.

- 4 Engel TR, Shah R, DePodesta LA, Frankl WS, Krause RL: T wave abnormalities of intermittent left bundle-branch block. Ann Intern Med 1978;89:204-206.

5 Wilson FN, MacLeod AG, Barker PS: T wave deflection of the electrocardiogram. Trans Assoc Am Physicians 1923;10:275-278.

6 Grimm W, Christ M, Maisch B: Long runs of non-sustained ventricular tachycardia on 24-hour ambulatory electrocardiogram predict major arrhythmic events in patients with idiopathic dilated cardiomyopathy. Pacing Clin Electrophysiol 2005;28(suppl 1): S207-S210.
7 Bazett HC: An analysis of time relations of the electrocardiogram. Heart 1920;7:353370.

8 Stein PK, Bosner MS, Kleiger RE, Conger BM: Heart rate variability: a measure of cardiac autonomic tone. Am Heart J 1994;127: 1376-1381.

-9 White WB, Dey HM, Schulman P: Assessment of the daily blood pressure load as a determinant of cardiac function in patients with mild-to-moderate hypertension. Am Heart J 1989;118:782-795.

10 Kalbfleisch SJ, Sousa J, El-Atassi R, Calkins H, Langberg J, Morady F: Repolarization abnormalities after catheter ablation of accessory atrioventricular connections with radiofrequency current. J Am Coll Cardiol 1991; 18:1761-1766.

11 Lepeschkin E: Electrocardiography. Baltimore, Williams \& Wilkins, 1951, pp 239420.

12 Kernohan RJ: Post-paroxysmal tachycardia syndrome. Br Heart J 1969;31:803-806.

13 Levine HD, Lown B, Streeper RB: The clinical significance of post-extrasystolic $\mathrm{T}$ wave changes. Circulation 1952;6:538-548.
14 Prinzen FW, Hunter WC, Wyman BT, McVeigh ER: Mapping of regional myocardial strain and work during ventricular pacing: experimental study using magnetic resonance imaging tagging. J Am Coll Cardiol 1999;33:1735-1742.

15 Sadoshima J, Izumo S: Molecular characterization of angiotensin II-induced hypertrophy of cardiac myocytes and hyperplasia of cardiac fibroblasts. Critical role of the AT1 receptor subtype. Circ Res 1993;73:413423.

16 Ricard P, Danilo P Jr, Cohen IS, Burkhoff D, Rosen MR: A role for the renin-angiotensin system in the evolution of cardiac memory. J Cardiovasc Electrophsyiol 1999;10:545551.

$>17$ Plotnikov AN, Yu H, Geller JC, Gainullin RZ, Chandra P, Patberg KW, Friezema S, Danilo P Jr, Cohen IS, Feinmark SJ , Rosen MR: Role of L-type calcium channels in pacing-induced short-term and long-term cardiac memory in canine heart. Circulation 2003;107:2844-2849.

18 Wendkos MH: The influence of autonomic imbalance on the human electrocardiogram. I. Unstable $T$ waves in precordial leads from emotionally unstable persons without heart organic disease. Am Heart J 1944;28:549556. 